\title{
Therapeutic Potential of Biologically Reduced Silver Nanoparticles from Actinomycete Cultures
}

\author{
M. K. Sukanya, ${ }^{1}$ K. A. Saju, ${ }^{1}$ P. K. Praseetha, ${ }^{2}$ and G. Sakthivel ${ }^{2}$ \\ ${ }^{1}$ Department of Biotechnology, Noorul Islam College of Arts and Sciences, Kumaracoil, Kanyakumari District, Tamil Nadu, India \\ ${ }^{2}$ Department of Nanotechnology, Noorul Islam Centre for Higher Education, Noorul Islam University, \\ Kumaracoil, Kanyakumari District, Tamil Nadu, India
}

Correspondence should be addressed to P. K. Praseetha; crkpkp@gmail.com

Received 29 April 2013; Revised 16 August 2013; Accepted 24 August 2013

Academic Editor: Kalimuthu Kalishwaralal

Copyright (c) 2013 M. K. Sukanya et al. This is an open access article distributed under the Creative Commons Attribution License, which permits unrestricted use, distribution, and reproduction in any medium, provided the original work is properly cited.

\begin{abstract}
Silver nanoparticles are applied in nanomedicine from time immemorial and are still used as powerful antibiotic and antiinflammatory agents. Antibiotics produced by actinomycetes are popular in almost all the therapeutic measures, and this study has proven that these microbes are also helpful in the biosynthesis of silver nanoparticles with good surface and size characteristics. Silver can be synthesized by various chemical methodologies, and most of them have turned to be toxic. This study has been successful in isolating the microbes from polluted environment, and subjecting them to the reduction of silver nanoparticles, characterizing the nanoparticles by UV spectrophotometry and transmission electron microscopy. The nanoparticles produced were tested for their antimicrobial property, and the zone of inhibition was greater than those produced by their chemically synthesized counterparts. Actinomycetes, helpful in bioremediating heavy metals, are useful for the production of metallic nanoparticles. The biosynthesized silver nanoparticles loaded with antibiotics prove to be better in killing the pathogens and have opened up new areas for developing nanobiotechnological research based on microbial applications.
\end{abstract}

\section{Introduction}

Human activities are greatly altering ecosystems worldwide at unprecedented rates, leading to accelerated loss of biodiversity [1] and environmental pollution. Soil is perhaps the most endangered component of our environment being open to potential contamination by a variety of different pollutants arising from human activities such as nuclear, industrial, and activities agricultural, $[2,3]$. There are hundreds of sources of heavy metal pollution, including the coal, natural gas, paper, and chloralkali industries [4]. "Heavy metals" is a general collective term, which applies to the group of metals and metalloids with atomic density greater than $4 \mathrm{~g} / \mathrm{cm}^{3}$, or 5 times or more, greater than water [5-7].

Microorganisms in the soil are responsible for nitrogen fixation, assimilation, and degradation of organic residues to release nutrients. Field studies of metal contaminated soils have demonstrated that elevated metal loadings can result in decreased microbial community [8-11]. Actinomycetes populations are relatively lower than other soil microbes and contain a predominance of streptomyces that are tolerant to acid conditions [12].

Classically the nanoparticles are produced by physical and chemical methods [13]. But these methods are costly, toxic, and nonecofriendly. Currently, there is a growing need to use environmentally friendly nanoparticles that do not produce toxic wastes in their process synthesis protocol. Silver has gained interest over the years because of its distinctive properties, such as good conductivity, chemical stability, and catalytic and antibacterial activity [14-16]. The current study throws light on silver nanoparticles (AgNPs) which are potentially been exploited in medicine for antibacterial, antifungal, antiviral, and anti-inflammatory therapy. The present study was carried out to determine the synthesis of AgNPs by actinomycetes from heavy metal-polluted sites exhibiting higher levels of antibacterial activity against human pathogens. The biosynthesized nanoparticles do have an enhanced therapeutic potential when compared to their chemically synthesized counterparts due to their small size and doping of natural antibiotics of actinomycete origin. 


\section{Material and Methods}

2.1. Sample Collection. Soil samples were collected for the isolation of actinomycetes from heavy metal-polluted and non-polluted areas. The heavy metal-polluted sample was collected from Travancore Titanium Products Ltd, Thiruvananthapuram, and nonpolluted sample was collected from Noorul Islam college of Arts and Science, Kumaracoil. The heavy metal-polluted and nonpolluted samples were randomly named as P and NP, respectively.

Each soil sample was taken from three different locations $(0.5 \mathrm{~km}$ intervals) of particular station from a depth of $10-$ $15 \mathrm{~cm}$ and mixed evenly. From the mixed sample $100 \mathrm{~g}$ were taken as a representative sample of the particular field. The soil samples were collected using clean, dry, and sterile polythene bags with a sterile spatula. The samples were immediately transported to the laboratory and stored in the refrigerator.

2.2. Physiochemical Analysis of Soil. The physiochemical characteristics such as soil color, soil texture, $\mathrm{pH}$, electrical conductivity (EC), organic carbon (OC), and nutrient content such as nitrogen, phosphorus, calcium, and magnesium of soil samples were estimated. The characteristics of the soil would definitely influence the type of microbes present in the environment, and the nutrient requirements for determining the growth characteristics of actinomycetes can be estimated by the same.

2.3. Population Density Study of Actinomycetes. Population density studies of actinomycetes were performed by serial dilution method. The number of microbial population per unit volume of sample is reduced by serial dilution for isolation of individual colonies. About $1 \mathrm{gm}$ of soil was transferred to conical flask containing $100 \mathrm{~mL}$ of sterile distilled water. This was then homogenized well for few minutes. $1 \mathrm{~mL}$ of homogenized sample was pipetted into a test tube labeled as $10^{-3}$ dilution. This procedure was repeated using sterile pipette for each dilution up to $10^{-7}$ dilution.

2.4. Isolation and Culture of Actinomycetes. Isolation of actinomycete cultures was done by plating technique in Potato Dextrose Agar (PDA) medium (supplemented with cyclohexamide $[25 \mu \mathrm{g} / \mathrm{mL}]$ and nalidixic acid $[10 \mu \mathrm{g} / \mathrm{mL}]$ as antifungal and antibacterial compounds, resp.). After obtaining satisfactory growth (requires about 7-14 days) the strains were subcultured in PDA slants in order to obtain pure culture. Pure isolates were maintained at $4^{\circ} \mathrm{C}$ in refrigerator for further studies.

2.5. Colony Characterization of Actinomycetes. Actinomycete isolates were observed using hand lens, and the colony morphology was recorded with respect to color, shape, size, and nature of the colony.

2.6. Microscopic Characterization. Actinomycete isolates were microscopically characterized by Lactophenol Cotton Blue mounting. The cell morphology was photographically recorded with respect to spore chain morphology and mycelium structure.

2.7. Carbohydrate Fermentation Test. Carbohydrate fermentation test was performed to confirm the actinomycete cultures up to genus level. Bushnell Hass Broth was prepared with sugars such as glucose, sucrose, lactose, arabinose, and dextrose. An indicator, phenol red, was mixed with the broth, and final $\mathrm{pH}$ was adjusted to 7.3. The test cultures were inoculated into appropriately labeled medium. All the tubes were incubated at room temperature for 7 days and were checked for a positive result of fermentation.

2.8. Starch Hydrolysis Test. The starch plate was inoculated with the organism to be tested. It was incubated at an optimum temperature of 48 hours. The plate was flooded with iodine, and the results were observed. Formation of blue color indicated that there was no hydrolysis, while a clear zone indicated hydrolysis.

\subsection{Sequence Analysis of $16 S$ rRNA Genes from Actinomycetes}

2.9.1. Extraction of Genomic DNA from Actinomycetes. It is important to taxonomically place the actinomycetes based upon their genus and species levels. The 16srRNA sequencing is the most reliable technique for taxonomically positioning the organisms. The actinomycete strain Streptomyces sp. II (NP1) was grown in $20 \mathrm{~mL}$ of actinomycete broth in $100 \mathrm{~mL}$ conical flask at $37^{\circ} \mathrm{C}$ in a rotary shaker $(200 \mathrm{rpm})$ for overnight. $1.5 \mathrm{~mL}$ of culture was transferred to the eppendorf tube and centrifuged at $8,000 \mathrm{rpm}$ for $2 \mathrm{~min}$. The supernatant was discarded and drained well onto a tissue paper. The pellet was resuspended in $400 \mu \mathrm{L}$ of sucrose TE buffer. To this, $32 \mu \mathrm{L}$ of lysozyme $(10 \mathrm{mg} / \mathrm{mL})$ was added and incubated the tubes at $37^{\circ} \mathrm{C}$ for $30 \mathrm{~min} .100 \mu \mathrm{L}$ of $0.5 \mathrm{M}$ EDTA at $\mathrm{pH} 8$ and $60 \mu \mathrm{L}$ of $10 \%$ SDS were added. To this, $1.5 \mu \mathrm{L}$ of proteinase $\mathrm{K}$ $\left(20 \mathrm{mg} \cdot \mathrm{mL}^{-1}\right)$ was added and incubated the tubes at $50^{\circ} \mathrm{C}$ (water bath) for $12 \mathrm{hrs}$. The tube was brought to room temperature, and $250 \mu \mathrm{L}$ of equilibrated phenol (equilibrated with Tris $\mathrm{HCl}$ ) was added and mixed well, and $250 \mu \mathrm{L}$ of chloroform was added. The solution was centrifuged at 10,000 rpm for $10 \mathrm{~min}$ and extracted twice with phenol chloroform $(1: 1$ ratio). The aqueous phase was extracted once again with chloroform isoamylalcohol (24:1 ratio), and the supernatant was collected and precipitated with 2 volume of absolute ethanol. The precipitate was centrifuged at $10,000 \mathrm{rpm}$ for $10 \mathrm{~min}$ and discarded the supernatant. Air dried it completely. The pellet was washed with $70 \%$ ethanol and allowed it to dry at room temperature. After complete drying, the pellet was dissolved in $20-50 \mu \mathrm{L}$ of sterile distilled water and stored at $-20^{\circ} \mathrm{C}$.

2.9.2. PCR Amplification of $16 S$ rRNA. The $16 \mathrm{~S}$ rRNA gene was amplified from genomic DNA obtained NP1 cultures by PCR with Universal Forward primer-16S rRNA F-5' AGAGTTTGA TCCTGGCTCAG- $3^{\prime}$ and Universal Reverse primer-16S rRNA R-5'-ACG GCT ACC TTG TTA CGA CTT-3'. The reaction mixture contained 25 to $50 \mathrm{ng}$ of DNA, Ex Taq PCR buffer, $1.5 \mathrm{mM} \mathrm{MgCl}_{2}, 10 \mathrm{mM}$ deoxynucleoside 
triphosphate mixture, $50 \mathrm{pmol}$ of each primer, and $0.5 \mathrm{U}$ of Ex Taq polymerase. PCR conditions consisted of an initial denaturation at $94^{\circ} \mathrm{C}$ for $5 \mathrm{~min} ; 30$ cycles at $94^{\circ} \mathrm{C}$ for $1 \mathrm{~min}$, annealing $58^{\circ} \mathrm{C}$ (THB-14), $63^{\circ} \mathrm{C}$ (ACT-20) for $1 \mathrm{~min}$, and $72^{\circ} \mathrm{C}$ for $1 \mathrm{~min}$, and final $5 \mathrm{~min}$ extension at $72^{\circ} \mathrm{C}$. The amplification products were examined by agarose gel electrophoresis and purified by using a QIA quick PCR clean-up kit with the protocol suggested by Qiagen Inc.

2.9.3. Sequencing of $16 \mathrm{~S} r$ RNA Genes. The complete $16 \mathrm{~S}$ rRNA gene was sequenced by using the PCR products directly as sequencing template with the above-mentioned primers. All sequencing reactions were carried out with an ABI 3730 automated DNA sequencer (Applied Biosystems, Monza, Italy).

2.9.4. Sequence and Phylogenetic Analysis. Nucleotide sequences were compared to those in the Gene Bank Database with the Basic Local Alignment Search Tool (BLAST) algorithm to identify known closely related sequences. The DNA sequences were aligned, and phylogenetic tree was constructed by neighbor joining method.

2.9.5. Screening of Actinomycetes for Reducing Activity. Screening of actinomycetes was performed using nitrate reduction test. Nitrate broth was used to determine the ability of an organism to reduce nitrate $\left(\mathrm{NO}_{3}\right)$ to nitrite $\left(\mathrm{NO}_{2}\right)$ using the enzyme nitrate reductase. Nitrate broth was prepared and sterilized properly. The isolated strains grown in PDA broth were subculture individually in $50 \mathrm{~mL}$ nitrate broth in $100 \mathrm{~mL}$ Erlenmeyer flask and incubated at $37^{\circ} \mathrm{C}$ for $24-48$ hours. At the end of incubation, $1 \mathrm{~mL}$ of alpha naphthylamine reagent and $1 \mathrm{~mL}$ of sulfanilic acid reagent were added to the test medium, and the color change was observed. If there was no change in color, zinc metal dust was sprinkled and observed for any notable changes.

\subsection{Biosynthesis of AgNPs}

2.10.1. Production of Actinomycete Biomass. Actinomycete cultures are required in considerable amounts for the purpose of biosynthesis. Hence it becomes essential to mass-culture the strains. For the production of biomass, the actinomycetes strains such as Streptomyces sp. I (P1), Rhodococcus sp. (P8), and Streptomyces sp. II (NP1) were grown aerobically in actinomycetes broth. The culture flasks were incubated in room temperature at $37^{\circ} \mathrm{C}$. After 15 days of incubation period, biomass was harvested using Whatman filter paper. The harvested biomass was washed with double-distilled water and filters the biomass. Then the filtered biomass was incubated in double distilled water for a day. After incubation, the biomass was separated from layer of water for further studies.

2.10.2. Synthesis of AgNPs. Actinomycete mat (20 gm) was obtained from actinomycete broth and used for the synthesis of AgNPs. The harvested cell filtrate was suspended in sterile double distilled water for 1 day. After one-day incubation, the cell filtrate (biomass) was obtained by passing it through
Whatman filter paper. 20 gm of biomass (fresh weight) was grind well using mortar and pestle and mixed with $200 \mathrm{~mL}$ of Millipore water in a $500 \mathrm{~mL}$ Erlenmeyer flask and agitated in the same condition for 72 hour at $37^{\circ} \mathrm{C}$. The same was repeated for the cell-free filtrate (filtered water) along with experimental flask $(20 \mathrm{~mL}$ filtered water in $200 \mathrm{~mL}$ of Millipore water). Biomass and water samples were randomly named as B and W.

For the synthesis of AgNPs, $50 \mathrm{~mL}$ of $1 \mathrm{mM} \mathrm{AgNO} 3$ solution was mixed with $50 \mathrm{~mL}$ of cell filtrate in a $250 \mathrm{~mL}$ Erlenmeyer flask and agitated at $37^{\circ} \mathrm{C}$ in darker condition. The same was done for the cell-free filtrate $(50 \mathrm{~mL}$ of $1 \mathrm{mM}$ $\mathrm{AgNO}_{3}$ solution with $50 \mathrm{~mL}$ filtered water). Simultaneously, control without silver ions was also run along with the experimental flasks. Colour change was noted at specific intervals (12 hours and 72 hours). The nanoparticles were characterized by UV-visible spectroscopy and transmission electron microscope (TEM) analysis.

\subsubsection{Characterization of Synthesized AgNPs}

2.10.4. UV-Visible Spectroscopic Analysis. The reduction of silver ions was confirmed by qualitative testing of supernatant by UV-visible spectrophotometer. $1 \mathrm{~mL}$ of sample supernatant was withdrawn after $24 \mathrm{hr}$, and absorbance was measured by using UV-visible spectrophotometer at a wavelength of $400-600 \mathrm{~nm}$.

2.10.5. Transmission Electron Microscopic Analysis of AgNPs. TEM analysis is a technique to examine the specimen structure, composition, or properties in nanometric levels. The cell-free filtrate of Streptomyces sp. II was treated with silver nitrate, and then the solution was centrifuged and washed with distilled water for 4-5 times. The pellet was collected and dried in hot air oven. The dried particles were scanned on a Philips transmission electron microscopy (TEM) at a magnification of $35000 \mathrm{X}$.

2.10.6. Protein Expression Studies. It becomes essential to understand the nature of the proteins which assist the reduction of AgNPs by the actinomycete strains. In order to compare the extracellular protein production and their molecular mass, the selected test strains (AgNPs synthesizing and nonsynthesizing) were subjected to SDS-Poly Acrylamide Gel Electrophoresis [SDS-PAGE], following the method of Laemmli (1970). Molecular weight markers for peptides ranging from $1 \mathrm{KDa}$ to $205 \mathrm{KDa}$ were used as protein markers.

2.10.7. Antibacterial Activity of Actinomycetes Strains and AgNPs against Human Pathogens. The antimicrobial activity of actinomycete strains and AgNPs against human pathogens such as Staphylococcus aureus, Klebsiella pneumonia, Proteus vulgaris, Pseudomonas aeruginosa, and Escherichia coli were obtained from ATCC and measured using disc diffusion method. Cultures of mentioned pathogens were grown in Muller-Hinton broth (Sigma, India) at $27^{\circ} \mathrm{C}$ on a rotary shaker at $200 \mathrm{rpm}$. $20 \mu \mathrm{L}$ of biosynthesized AgNPs solution 


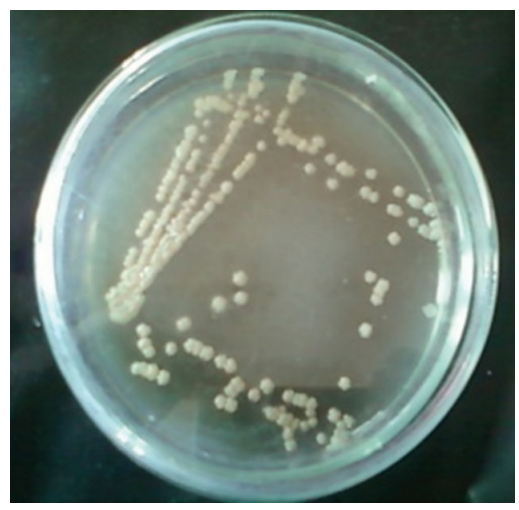

(a) Streptomyces sp. $1(\mathrm{Pl})$

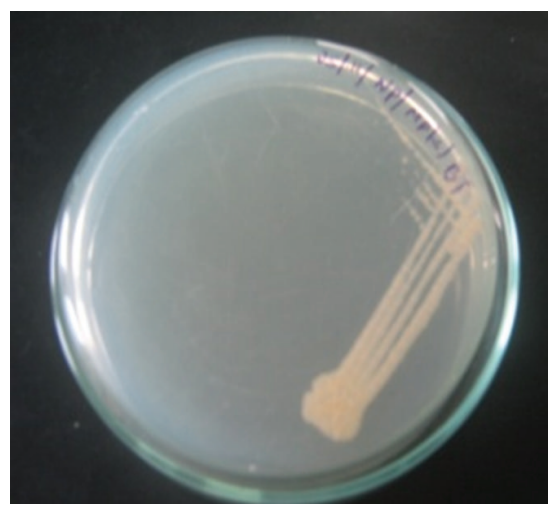

(b) Rhodococcus sp. (P8)

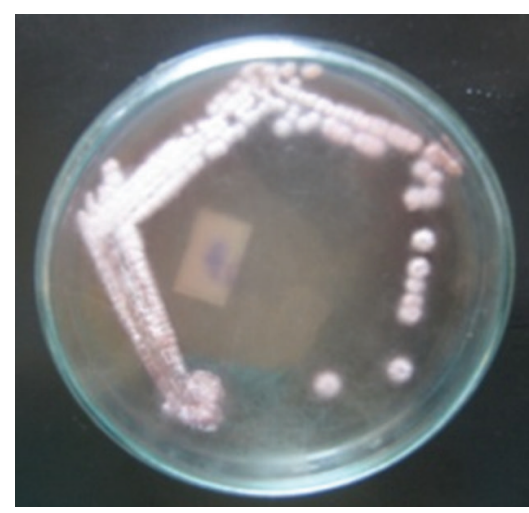

(c) Streptomyces sp. II (NP1)

FIGURE 1: Colony morphology and microscopic view of actinomycetes.

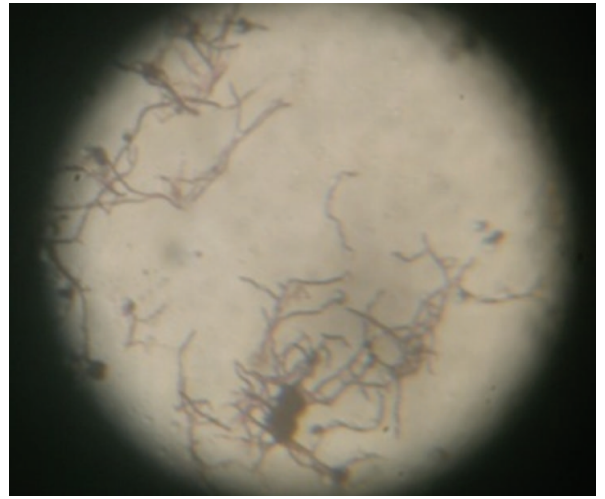

(a) Streptomyces sp. 1 (P1)

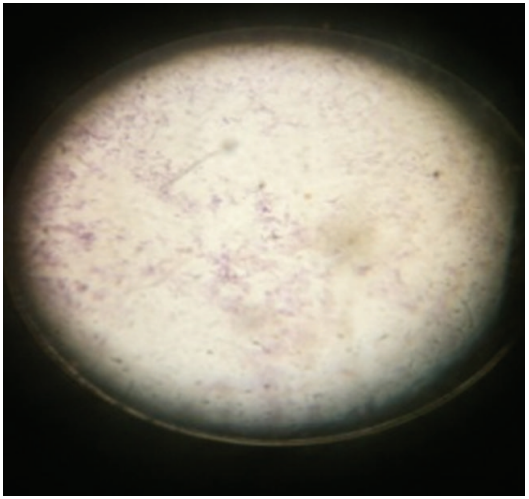

(b) Rhodococcus sp. (P8)

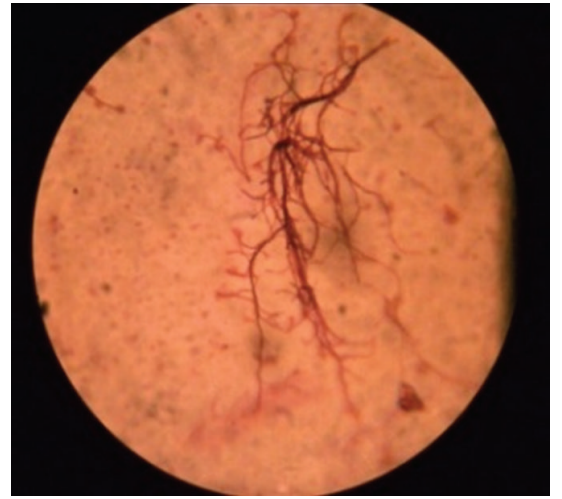

(c) Streptomyces sp. II (NP1)

FIgURE 2: Microscopic observations of cultured actinomycete.

was added into each disc. After incubation the diameter of the inhibition zones was measured.

\section{Results}

Actinomycete strains isolated from the soil samples were collected from heavy metal-polluted and nonpolluted soil. The actinomycete isolates were characterized on the basis of colony characterization, macroscopic appearance, and biochemical test such as carbohydrate and starch hydrolysis test.

3.1. Isolation and Identification of Actinomycetes. Four genera of actinomycetes which included 10 different species were isolated from the heavy metal-polluted and nonpolluted soil samples. The species identified in the nonpolluted soil were Streptomyces sp. I (NP4), Streptomyces sp. II (NP1), Streptomyces sp. III (NP10), Rothia sp. (NP5), Actinomadura sp. (NP2), and Rhodococcus sp. (NP7). In the heavy metalpolluted soil sample four species were identified which were Streptomyces sp. I (P1), Streptomyces sp. II (P2), Streptomyces sp. III (P3), and Rhodococcus sp. (P8). The results revealed that Streptomyces sp. was the predominant actinomycete in both the soil samples. Though the actinomycetes belong to the same genera, the species identified from the nonpolluted soil differed in the morphological and biochemical characteristics of the same species of the same genera identified from the heavy metal-polluted soil. The results of the present investigation (Figures 1 and 2) show that all the actinomycetes showed branched, filamentous, fragmented, separated, or long mycelium arrangement.

3.2. Biosynthesis of AgNPs. The color change (brown colour) occurred in the biomass and cell-free extract when challenged with $1 \mathrm{mM} \mathrm{AgNO} 3$ (Figures 3(a) to 3(d)) in $48 \mathrm{hrs}$ and attained maximum intensity after $72 \mathrm{hrs}$. The increase in intensity during the period of incubation indicated the formation of AgNPs. The production of silver nanoparticles is higher in cell-free filtrates than in biomass samples. Control without silver ions showed no change in color when incubated under the same conditions.

3.3. Characterization of Silver Nanoparticle by UV-Vis Spectroscopy. The light absorption patterns of the cell filtrate and cell-free filtrate of actinomycetes were monitored after 72 hours in the range of $290-600 \mathrm{~nm}$ by using UV-visible spectrophotometer. UV-visible absorption spectra of AgNPs are 


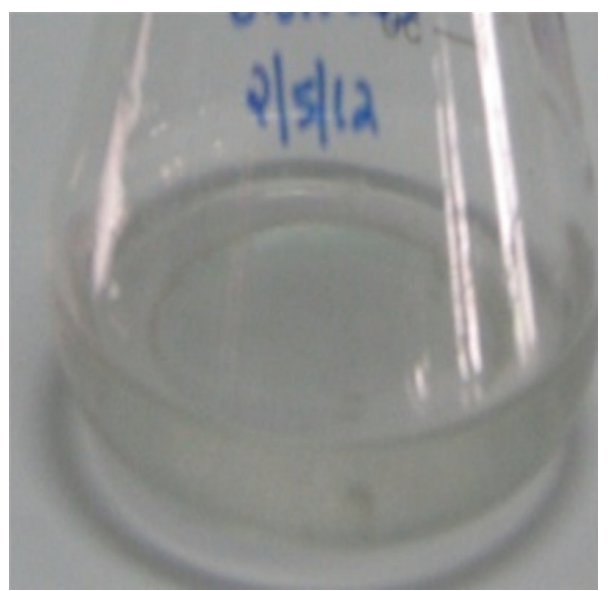

(a) Control (without $\mathrm{AgNO}_{3}$ )

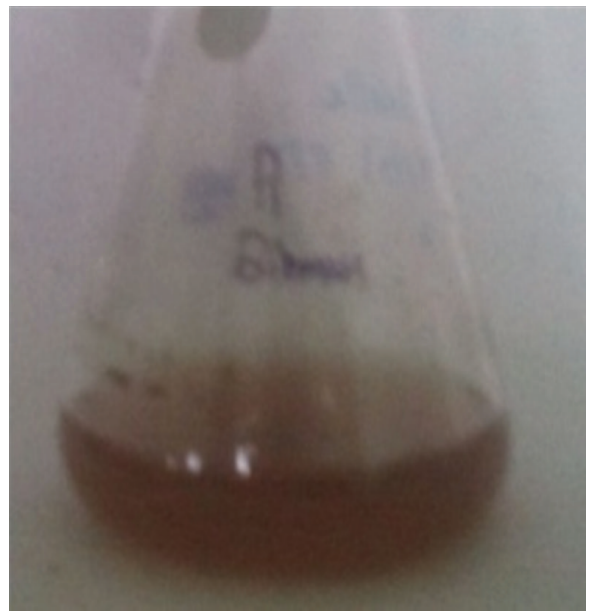

(c) Cell filtrate after 48 hours

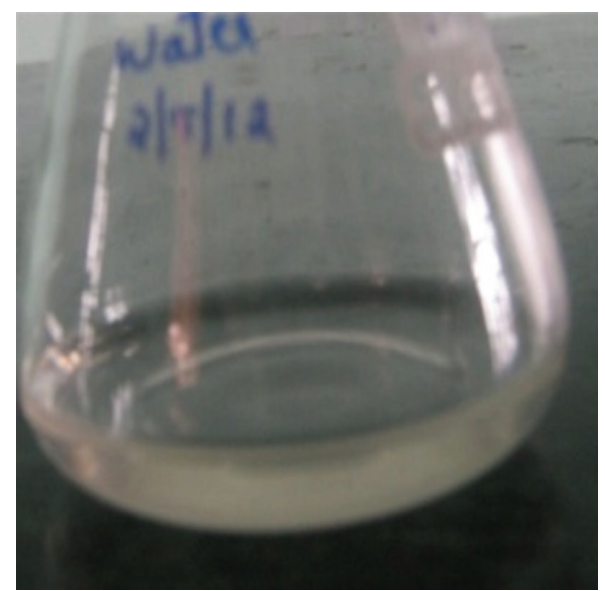

(b) At the beginning of the reaction

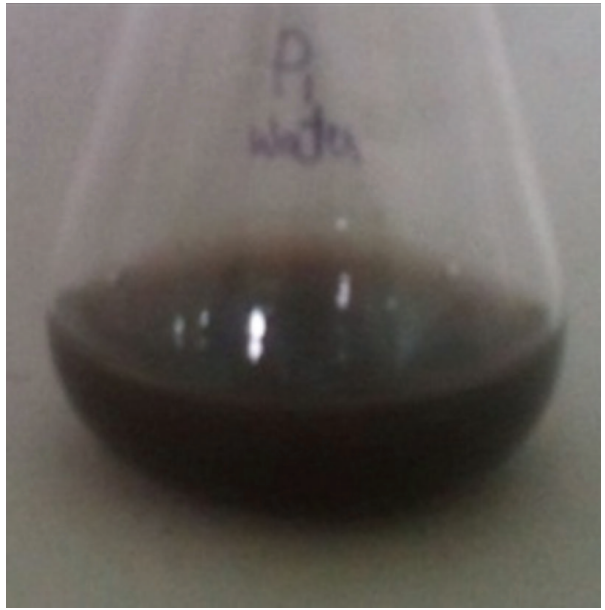

(d) Cell-free filtrate after 72 hours

Figure 3: Biosynthesis of AgNPs by actinomycete strains.

shown in Figure 4. Biosynthesis of AgNPs from cellfree filtrate of actinomycete showed an intense peak at $450 \mathrm{~nm}$ for the sample WNP1 at wavelength range of $400-500 \mathrm{~nm}$.

\subsection{Transmission Electron Microscopic Studies (TEM) of Syn-} thesized AgNPs. TEM image of biosynthesized AgNPs was obtained by using cell-free filtrate of Streptomyces sp. II after reacting with silver nitrate. The size of the particles ranged from 5 to $40 \mathrm{~nm}$. The nanoparticles were observed to be spherical. The observations can be made from Figure 5 .

\subsection{Protein Expression Studies. Polyacrylamide gel Electro-} phoresis was used to assess the compounds produced during biosynthesis of AgNPs. Separate protein bands were visualized for the actinomycete strains that produce nanoparticles on staining the gel, which was absent in the actinomycete strains lacking the reduction activity. Few bands were noted with molecular weights 20 and $30 \mathrm{kDa}$. Figure 6 explains the details.
3.6. Antibacterial Activity of AgNPs and Actinomycetes Strains against Human Pathogens. The antibacterial activity of actinomycetes was investigated against various pathogenic bacteria of Gram-positive (Staphylococcus aureus) and Gramnegative (E. coli, Pseudomonas aeruginosa, Klebsiella pneumonia and Proteus vulgaris) strains using disc diffusion method (Table 1). Out of the three actinomycete isolates, Streptomyces sp. I (P1) exhibited maximum antibacterial activity against Pseudomonas aeruginosa $(10 \mathrm{~mm})$. The details are depicted in Table 1 and Figure 7(a) to 7(e).

The antibacterial activity of AgNPs was investigated against various pathogenic bacteria. The highest antimicrobial activity was observed against Pseudomonas aeruginosa followed by Staphylococcus aureus and Klebsiella pneumonia. The antibacterial activity of the bionanoparticles for Pseudomonas aerogenosa was the maximum $(26 \mathrm{~mm})$ followed by Staphylococcus aureus $(23 \mathrm{~mm})$, Klebsiella Pneumonia $(21 \mathrm{~mm})$, and E. coli $(19 \mathrm{~mm})$. Compared to the commercial antibiotics like kanamycin which produces inhibition zones in the order of $22 \mathrm{~mm}, 18 \mathrm{~mm}, 21 \mathrm{~mm}$, and $16 \mathrm{~mm}$ for the pathogens, silver nanoparticles exhibited better killing efficiency. 
TABLE 1: Antibacterial activity of AgNPs against pathogenic bacteria.

\begin{tabular}{|c|c|c|c|c|c|c|}
\hline \multirow{2}{*}{ Sl. no } & \multirow{2}{*}{ Strains } & \multicolumn{5}{|c|}{ Diameter of zone of inhibition ( $\mathrm{mm}$ ) } \\
\hline & & E. coli & Staphylococcus aureus & Pseudomonas aeruginosa & Klebsiella pneumoniae & Proteus vulgaris \\
\hline 1 & BP1 & 19 & 20 & 20 & 17 & - \\
\hline 2 & BP8 & 16 & 21 & 26 & 20 & - \\
\hline 3 & BNP1 & 16 & 20 & 24 & 21 & - \\
\hline 4 & WP1 & - & 21 & 18 & - & - \\
\hline 5 & WP8 & - & 23 & 18 & 18 & - \\
\hline 6 & WNP1 & - & 20 & 22 & 19 & 9 \\
\hline 7 & Control & - & - & - & - & - \\
\hline
\end{tabular}

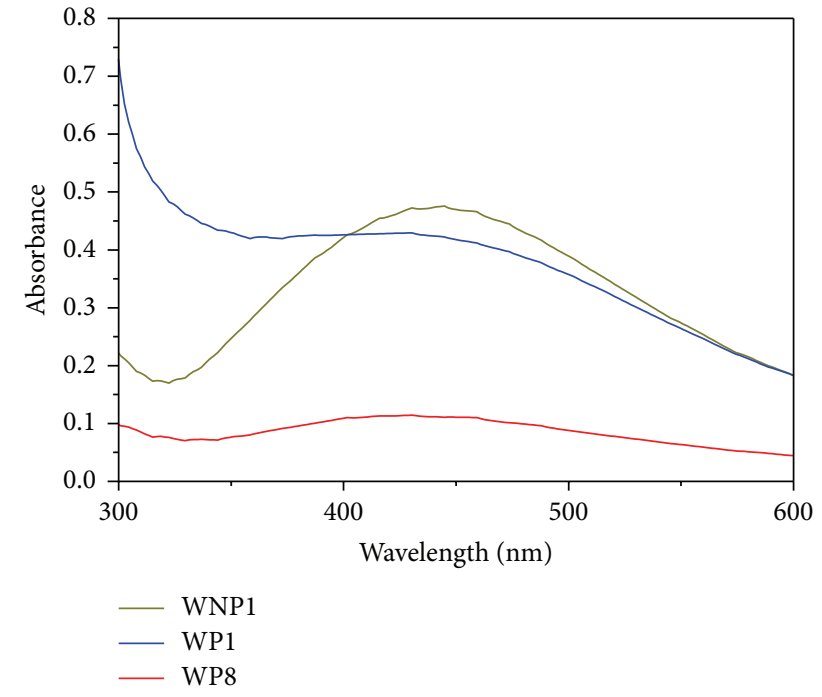

FIGURE 4: UV-visible spectrum of AgNPs synthesized by different actinomycete strains.

This test shows that silver nanoparticles are nearly $70 \%$, $85 \%$, and $60 \%$ effective compared to Kanamycin and Arithromycin, respectively.

\section{Discussions and Conclusion}

The actinomycete species that showed positive result in nitrate reduction test were screened and selected for the production of silver nanoparticles. Streptomyces sp. I, Streptomyces sp. II, and Rhodococcus sp. were further selected for the biosynthesis of AgNPs.

The results revealed that Streptomyces sp. was the predominant actinomycete in both soil samples. Though the actinomycetes belong to the same genera, the species identified from the nonpolluted soil differed in the morphological and biochemical characteristics of the same species of the same genera identified from the heavy metal-polluted soil. The results of the present investigation show that all the actinomycetes showed branched, filamentous, fragmented, separated, or long mycelium arrangement which falls in line with the findings of [17]. The identification of actinomycetes was carried out using the references [18-20]. The strain isolated, Streptomyces sp. II (NP1), was confirmed using 16S

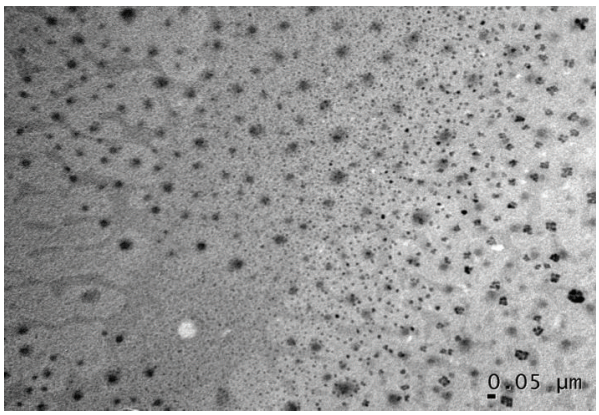

FIGURE 5: Size measurement of silver nanoparticles by transmission electron microscopy.

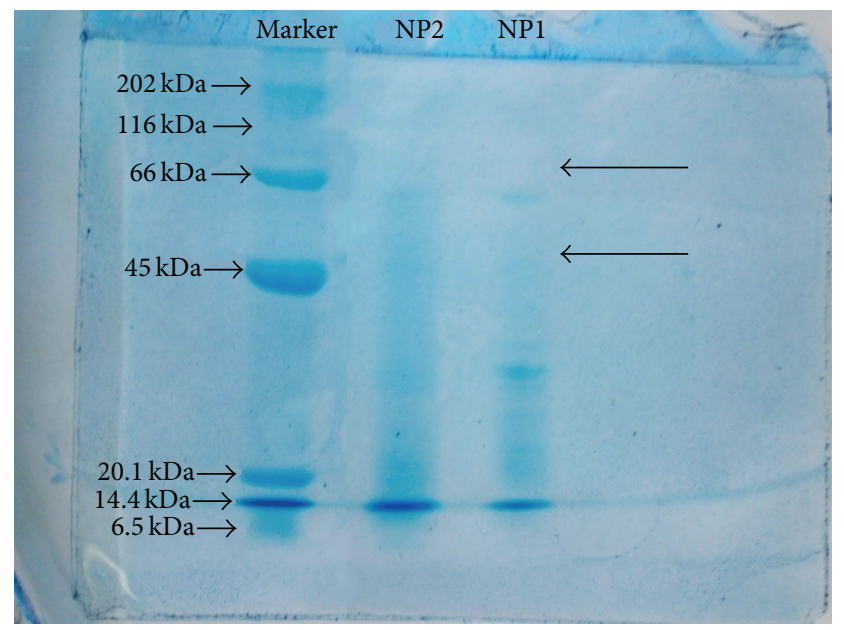

Figure 6: Protein bands produced by the actinomycete strains.

rRNA sequence analysis. Based on 16srRNA sequence and phylogenetic analysis, Streptomyces sp. II (NP1) isolated from nonpolluted soil was confirmed as Streptomyces lomondensis.

UV studies with WNP1 sample showed an intense peak at $450 \mathrm{~nm}$, which proves the presence of AgNPs [21]. The production of silver nanoparticles was further confirmed by obtaining a TEM image. The size of particles ranged from 65 to $80 \mathrm{~nm}$. The nanoparticles were observed to be spherical [22]. The study also revealed that specific proteins were synthesized by the actinomycetes when they were involved in the production of nanoparticles. The molecular weight of 


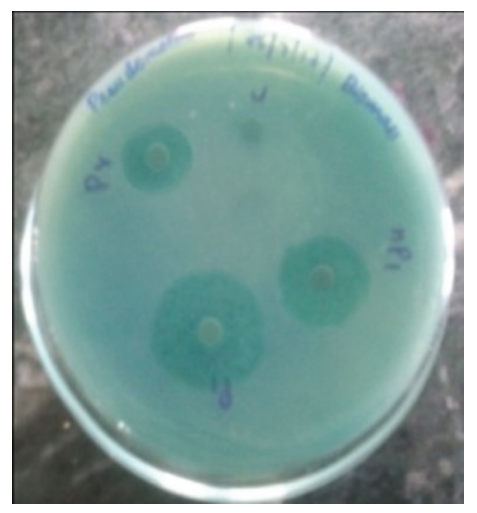

(a)

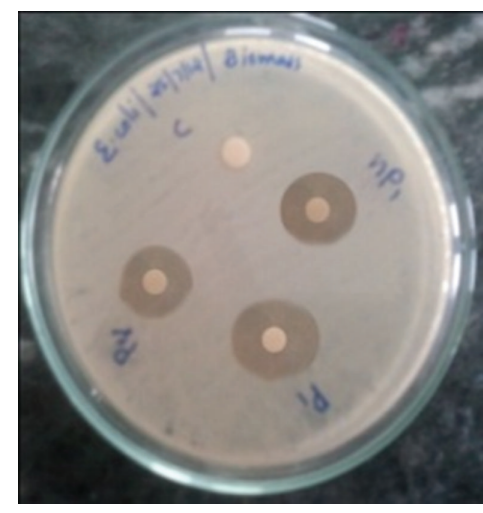

(b)

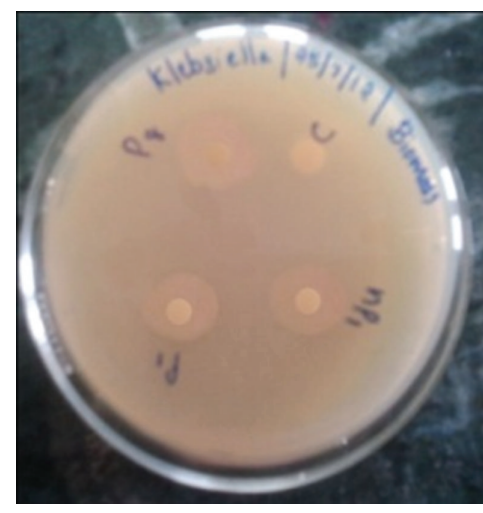

(c)

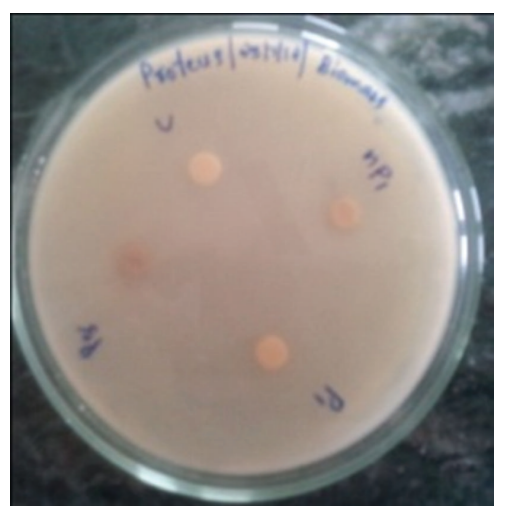

(d)

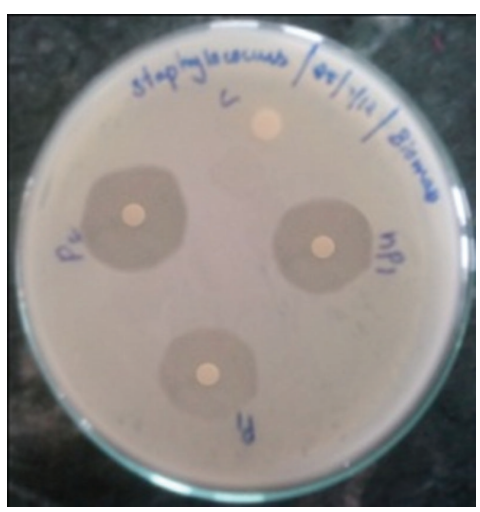

(e)

FIGURE 7: Inhibition zones produced by biosynthesized AgNPs against different bacterial strains.

the protein bands revealed a similarity to heat shock proteins. These are stress-related proteins which assist in the reduction of silver nanoparticles.

Streptomyces sp. was highly susceptible to Gram-positive bacteria and showed moderate activity against Gram-negative bacteria [23]. Rhodococcus sp. also produced antibacterial activity against pathogenic bacteria [24]. Many researchers [25] used Escherichia coli as a model for Gram-negative bacteria and proved that AgNPs may be used as an antimicrobial agent.

As the microbes are well adapted to heavy metal degradation, they are capable of reducing silver nitrate to AgNPs. Silver nanoparticles by nature do have an antibacterial property. These nanoparticles synthesized by actinomycetes are loaded with antibiotic substances during biosynthesis. Thus the antibiotic effect of biosynthesized silver nanoparticles is better than silver nanoparticles produced by chemical methods.

\section{Acknowledgments}

The authors deeply acknowledge Noorul Islam University for support extended to perform the current study. They thank the Department of Biotechnology, Rajiv Gandhi Centre for Biotechnology, Thiruvananthapuram, for analyzing data using TEM.

\section{References}

[1] P. H. Raven, "Science, sustainability, and the human prospect," Science, vol. 297, pp. 954-958, 2002.

[2] O. Morton-Bermea, E. Hernández Álvarez, I. Gaso, and N. Segovia, "Heavy metal concentrations in surface soils from Mexico City," Bulletin of Environmental Contamination and Toxicology, vol. 68, no. 3, pp. 383-388, 2002.

[3] M. R. Kalantari, M. Shokrzadeh, A. G. Ebadi, C. Mohammadizadeh, M. I. Choudhary, and A.-U. Atta-ur-Rahman, "Soil pollution by heavy metals and remediation (Mazandaran-Iran)," Journal of Applied Sciences, vol. 6, no. 9, pp. 2110-2116, 2006.

[4] D. G. McDonald and A. F. Grandt, "Limestone- Lime Treatment of Acid Mine Drainage-Full Scale," EPA Project Summary, EPA600/S7-81-033, 1981.

[5] J. O. Nriagu, "A global assessment of natural sources of atmospheric trace metals," Nature, vol. 338, no. 6210, pp. 47-49, 1989.

[6] J. R. Garbarino, H. Hayes, D. Roth, R. Antweider, T. I. Brinton, and H. Taylor, Contaminants in the Mississippi River, U. S. Geological Survey Circular 1133, Virginia, Va, USA, 1995.

[7] S. J. Hawkes, "What is a "Heavy Metal"?" Journal of Chemical Education, vol. 74, no. 11, p. 1374, 1997.

[8] M. J. Jordan and M. P. Lechevalier, "Effects of zinc smelter emissions on forest soil microflora," Canadian Journal of Microbiology, vol. 21, no. 11, pp. 1855-1865, 1975.

[9] P. C. Brookes and S. P. McGrath, "Effects of metal toxicity on the size of the soil microbial biomass," Journal of Soil Science, vol. 35, no. 2, pp. 341-346, 1984. 
[10] K. Chander and P. C. Brookes, "Effects of heavy metals from past applications of sewage sludge on microbial biomass and organic matter accumulation in a sandy loam and silty loam U.K. soil," Soil Biology and Biochemistry, vol. 23, no. 10, pp. 927-932, 1991.

[11] A. Konopka, T. Zakharova, M. Bischoff, L. Oliver, C. Nakatsu, and R. F. Turco, "Microbial biomass and activity in lead-contaminated soil," Applied and Environmental Microbiology, vol. 65, no. 5, pp. 2256-2259, 1999.

[12] F. L. Davies and S. T. Williams, "Studies on the ecology of actinomycetes in soil. I. The occurrence and distribution of actinomycetes in a pine forest soil," Soil Biology and Biochemistry, vol. 2, no. 4, pp. 227-238, 1970.

[13] Z.-J. Jiang, C.-Y. Liu, and L.-W. Sun, "Catalytic properties of silver nanoparticles supported on silica spheres," Journal of Physical Chemistry B, vol. 109, no. 5, pp. 1730-1735, 2005.

[14] P. Mukherjee, A. Ahmad, D. Mandal et al., "Fungus-mediated synthesis of silver nanoparticles and their immobilization in the mycelial matrix: a novel biological approach to nanoparticle synthesis," Nano Letters, vol. 1, no. 10, pp. 515-519, 2001.

[15] I. Sondi and B. Salopek-Sondi, "Silver nanoparticles as antimicrobial agent: a case study on E. coli as a model for Gramnegative bacteria," Journal of Colloid and Interface Science, vol. 275, no. 1, pp. 177-182, 2004.

[16] X. Chen and H. J. Schluesener, "Nanosilver: a nanoproduct in medical application," Toxicology Letters, vol. 176, no. 1, pp. 1-12, 2008.

[17] M. Buée, P. E. Courty, D. Mignot, and J. Garbaye, "Soil niche effect on species diversity and catabolic activities in an ectomycorrhizal fungal community," Soil Biology and Biochemistry, vol. 39, no. 8, pp. 1947-1955, 2007.

[18] R. E. Buchanan and N. E. Gibbons, Bergey's Manual of Determinative Bacteriology, 8th edition, 1974.

[19] L. Sembiring, Selective isolation and characterisation of streptomycetes associated with the rhizosphere of the tropical legume, Paraserianthes falcataria (L) Nielsen [Ph.D. thesis], University of Newcastle, Tyne, UK, 2003.

[20] M. George, A. Anjumol, G. George, and A. A. M. Hatha, "Distribution and bioactive potential of soil actinomycetes from different ecological habitats," Journal of Microbiology Research, vol. 6, no. 10, pp. 2265-2271, 2011.

[21] P. Mulvaney, "Surface plasmon spectroscopy of nanosized metal particles," Langmuir, vol. 12, no. 3, pp. 788-800, 1996.

[22] N. Y. Tsibakhashvili, E. I. Kirkesali, D. T. Pataraya et al., "Microbial synthesis of silver nanoparticles by Streptomyces glaucus and Spirulina platensis," Advanced Science Letters, vol. 4, no. 1112, pp. 3408-3417, 2011.

[23] K. J. Narayana, P. Prabhakar, M. Vijayalakshmi, Y. Venkateswarlu, and P. S. Krishna, "Biological activity of phenylpropionic acid isolated from a terrestrial Streptomycetes," Polish Journal of Microbiology, vol. 56, no. 3, pp. 191-197, 2007.

[24] L. S. Singh, I. Baruah, and T. C. Bora, "Actinomycetes of Loktak habitat: isolation and screening for antimicrobial activities," Biotechnology, vol. 5, no. 2, pp. 217-221, 2006.

[25] Q. L. Feng, J. Wa, G. Q. Chen, K. Z. Cui, T. M. Kim, and J. O. Kim, "Antimicrobial activity of silver nanoparticles against bacterial species," Journal of Biomedical Materials Research B, no. 52, pp. 662-668, 2003. 

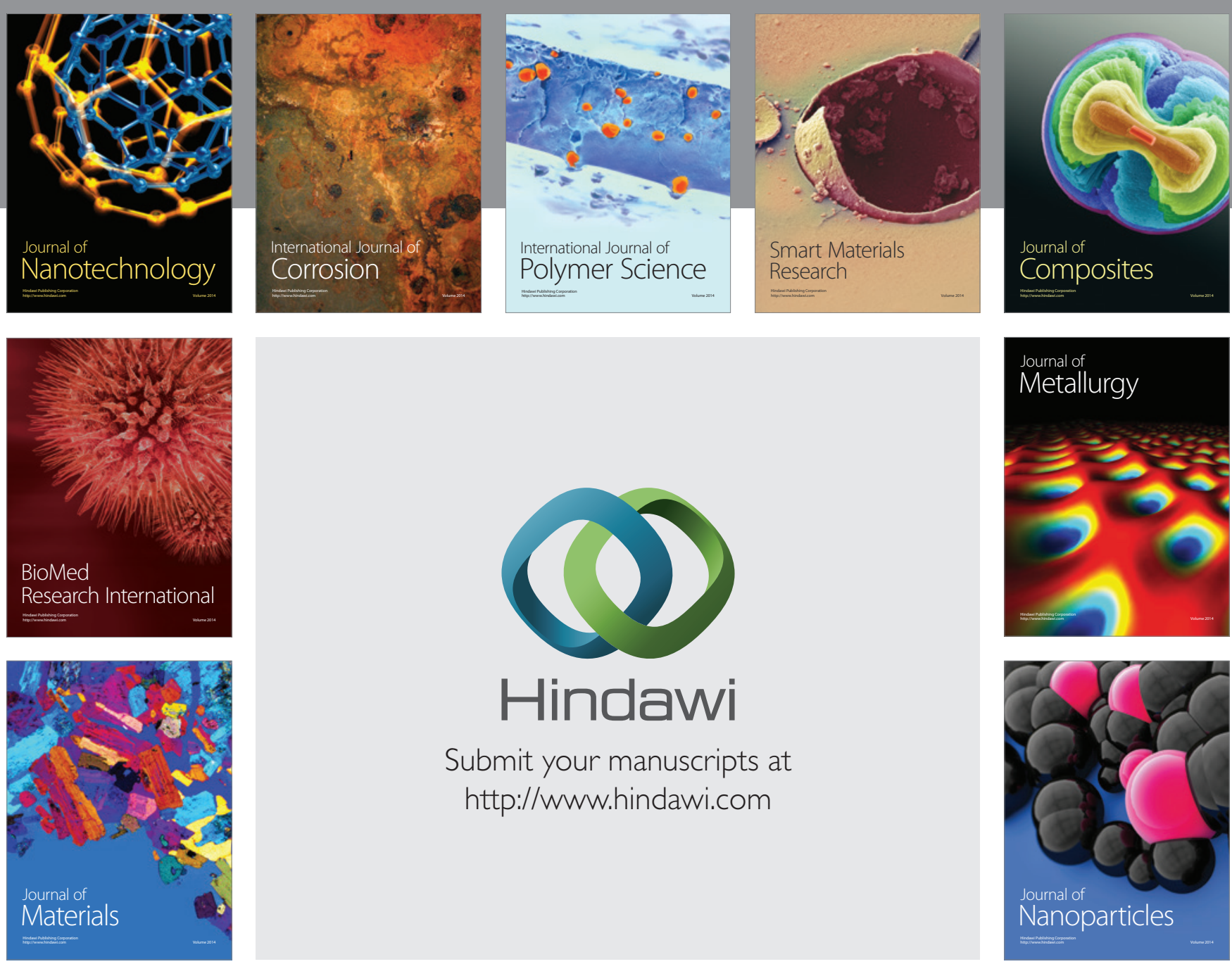

Submit your manuscripts at http://www.hindawi.com
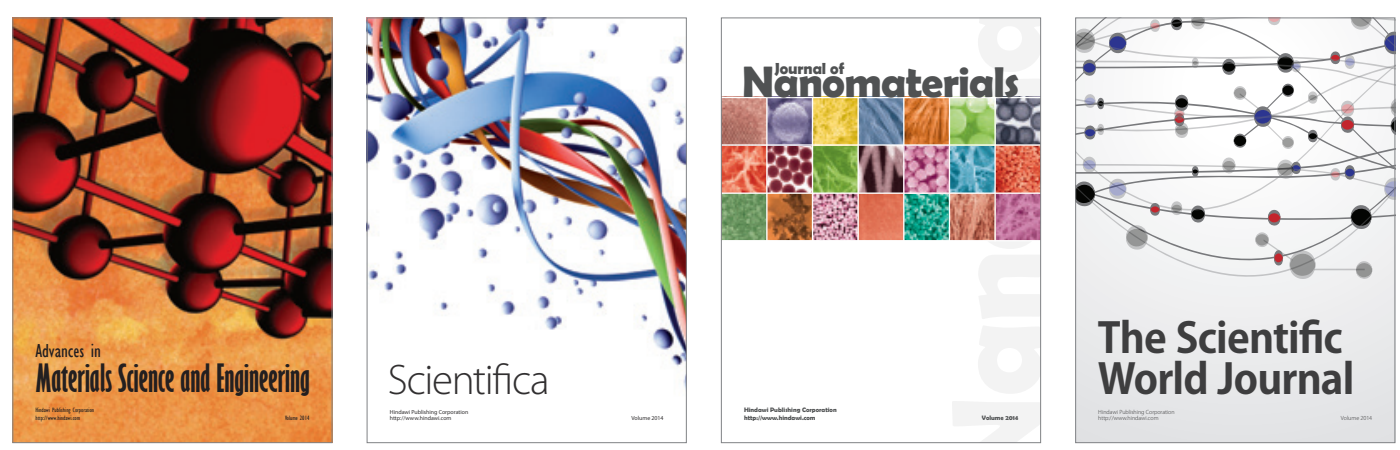

\section{The Scientific World Journal}
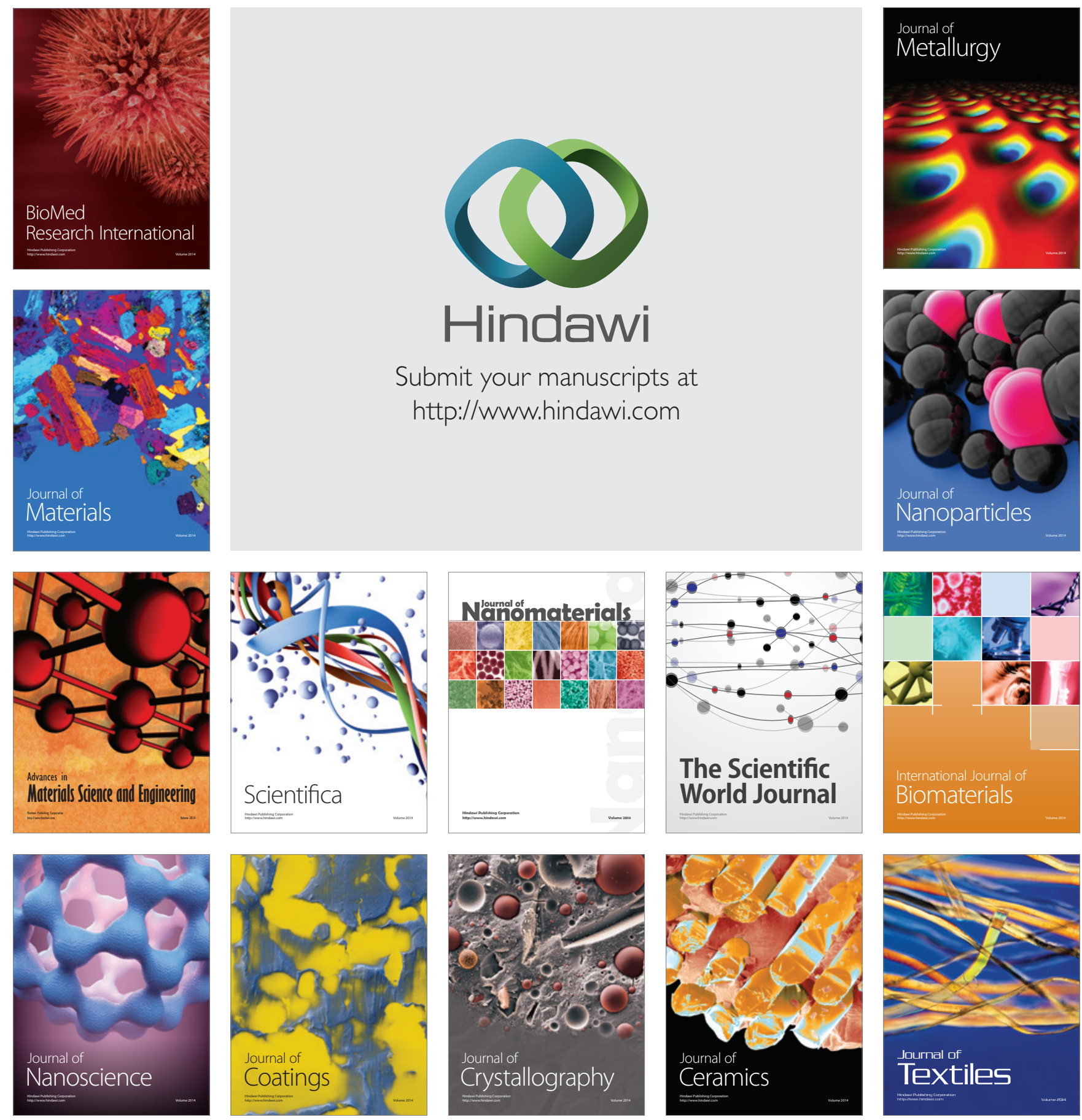